\title{
A comparative review of the literature surrounding complications associated with Percutaneous Dilatational Tracheostomy versus Open Surgical Tracheostomy SSM2
}

\author{
Holly Newton, 2nd year medical student, Shadaba Ahmed FRCS, ORL-HNS ENT Consultant
}

\begin{abstract}
In this structured review, I aim to discuss the principle of tracheostomies including what they are and why we perform them. My main objective is to explore the literature surrounding whether or not there is a better option between open surgical and percutaneous dilatational tracheostomy, based on the complications with which they are associated. Simply put, a tracheostomy is a common surgical procedure performed on critically ill patients in order to facilitate their breathing. I will discuss the two main types of tracheostomy: open surgical (OST) and percutaneous dilatational (PDT), along with their accompanying impediments.
\end{abstract}

To write this review, I read and analysed numerous articles and journals in order to find out what research has been done in this area and what the current consensus is amongst healthcare professionals. To find relevant literature, I methodically searched several medical databases including PubMed, Medline, The Cochrane Library and Embase. I decided to exclude any literature dating back further than 2002, as I wanted my review to be based on recent findings in order for it to be more reliable.

My main findings were that the complication rates for open surgical tracheostomy showed no substantial difference to those seen in percutaneous dilatational tracheostomy. There were studies that disagreed with this conclusion; however, I believe this to be more down to the patient's state of health and their reason for needing a tracheostomy rather than the technique itself. The main advantage to PDT was that it doesn't involve transfer of the patient to an operating room and therefore it saves time, money and lessens the physical stress on the patient. For these reasons, percutaneous dilatational tracheostomy has largely increased in popularity in recent times. Despite this, there are still some situations in which OST is the method of choice, the character of which will be discussed in this review.

\section{INTRODUCTION}

Tracheostomy is a term describing a surgical procedure in which an opening is made in the anterior neck, within which a tube is inserted into the trachea to facilitate ventilation. $^{2}$ It is one of the most commonly performed procedures to be carried out on critically ill patients, with two thirds being completed in the Intensive Care Unit (ICU). ${ }^{3}$

\section{Anatomy}

To understand tracheostomies, and the complications that can arise from them, it is important that we first understand the anatomy of the neck.
The neck has four main compartments: a vertebral, a visceral and two vascular. The trachea is located in the visceral compartment along with the oesophagus, thyroid, parathyroid and thymus glands. The respiratory tract can be divided into an upper and a lower region, beginning at the nasal cavity and terminating at the alveoli. The inhaled air now passes into the larynx, which is connected inferiorly to the trachea, both of which are situated anteriorly to the oesophagus.

The larynx represents the superior section of the lower respiratory tract. Essentially, it has two functions: it acts as an instrument to produce sound and allow us to speak and also functions as a sphincter to close off the lower airway for protection. The larynx is composed of three large unpaired cartilages (thyroid, cricoid and epiglottis) and three smaller, paired cartilages (arytenoids, corniculate and cuniform).

In the neck, there are two important vertebral levels that serve as anatomical indicators when performing surgery:

1. CIII to CIV - between these two vertebrae we would find the superior border of the thyroid cartilage as well as the point in which the common carotid artery bifurcates into the internal and external carotid arteries.

2. CV to CVI - this area denotes the lower limit of the larynx and the superior limit of both the trachea and oesophagus.

In terms of blood supply to the neck, potential bleeding complications can arise from two main vessels. There is the external carotid artery, and the innominate artery, which passes anteriorly to the lower tracheal rings. As well as the jugular veins situated in this region. ${ }^{4,5}$

When performing a tracheostomy to stay in the midline, there are several key structures to identify:

- Hyoid bone

- Thyroid cartilage

- Cricothyroid membrane

- Cricoid cartilage

- Tracheal cartilages

- We can palpate the indentation present between the cricoid cartilage of the larynx and the first tracheal ring. As the trachea descends into the chest, it becomes increasingly difficult to palpate.

- The final noticeable palpable landmark is the suprasternal notch, which signifies the junction between the neck and chest. 


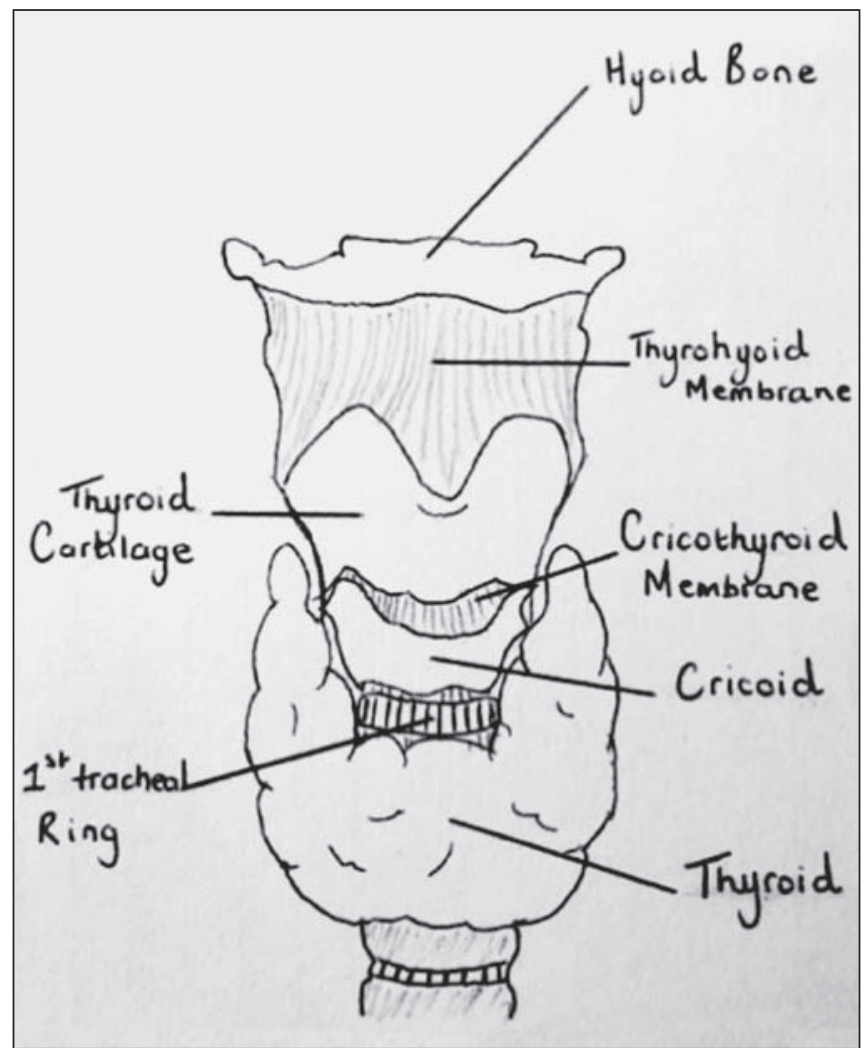

Figure 1: I have illustrated the important structures present in the neck to allow for a visual representation of the anatomy discussed: The hyoid bone, thyroid and cricoid cartilages with their associated membranes, first tracheal ring and thyroid gland

Tracheostomy is most commonly executed between the second and third tracheal rings however; it can also be done between the third and fourth. At the recommended site for tube insertion, the trachea is approximately $2-2.5 \mathrm{~cm}$ deep from the skins surface. In terms of complications, it is vital that we understand the positioning of the oesophagus in that it is directly posterior to the trachea. Therefore, any damage to the posterior tracheal wall risks injury to the oesophagus. We must also consider the proximity of structures such as the thyroid isthmus, which lies over the second/third tracheal rings and also the lateral lobes of the thyroid, which lie close to this. In most patients, the midline lacks vasculature, however this is not true in all cases and so there is debate surrounding the use of real time ultrasound guidance to help with this procedure. As well as blood vessels, there are particular nerves that are of importance in the neck. The recurrent laryngeal nerve is located within the tracheoesophageal grooves and is at risk. ${ }^{6,7}$

\section{Tracheostomies: their history, clinical relevance, indications and potential complications}

Tracheostomies are said to date back as far as 3600 B.C.E, making them one of the earliest surgical procedures to ever be performed..$^{7,8}$ Traditionally, tracheostomies were almost all performed by ENT surgeons in an operating theatre. However, in the last 50 years, there has been a shift towards tracheostomies being done at the patient's bedside by alternative professionals such as anaesthetists.
This sparked a debate surrounding whether or not PDT(percutaneous dilatational tracheostomy) is as safe a procedure as $\mathrm{OST}^{3}$ (open surgical tracheostomy.

Performing a tracheostomy on a critically ill patient is of course associated with numerous potential risks yet, it also provides many benefits for the patient. It is widely accepted that the benefits largely outweigh the risks and hence, it is estimated that 15,000 tracheostomies are done in England and Wales each year. Benefits include increased patient comfort, decrease in dead space and a reduction in the need for sedation of the patient. All of these facilitate the process of weaning the patient from oxygen, which is the ultimate aim for any patient on oxygen therapy. ${ }^{8,10}$

Essentially, there are two types of tracheostomies: open surgical tracheostomy (OST) and percutaneous dilatational tracheostomy (PDT). We can define OST as a procedure in which an incision is made into the tracheal wall, following dissection of pretracheal tissues and the subsequent placement of a cannula into the trachea, often done under direct vision i.e. with bronchoscopic guidance. In contrast, PDT describes the blunt dissection of pretracheal tissues, then the dilatation of the trachea over the guidewire and finally the insertion of the tracheal cannula using the Seldinger technique. ${ }^{11}$

There are several indications for which a tracheostomy should be performed: ${ }^{3}$

- The requirement for long-term mechanical ventilation, which may be due to conditions such as acute respiratory distress syndrome, severe COPD, brain damage or multiple organ failure. ${ }^{12,13}$ This is the most common motivation for patients to have a tracheostomy.

- An upper respiratory tract obstruction

- The need for frequent suctioning for bronchopulmonary toileting

Despite the fact that PDT is overtaking OST as a method for performing tracheostomies, there are certain situations in which we would place preference on open surgical tracheostomy: ${ }^{14}$

- Patients with difficult neck anatomy (e.g. calcified tracheal rings or patients whose necks are short and thick)

- Obese patients

- Young children

- Patients suffering with head/neck difficulties e.g. a thyroid goitre

It should also be noted that percutaneous tracheostomies are avoided in emergency situations. ${ }^{15}$

Although surgical tracheostomies have been around for hundreds of years, it was Chevalier Jackson who standardised the skill of open surgical tracheostomy in $1909 .{ }^{16}$ Ciaglia first introduced the concept of percutaneous dilatational tracheostomy in 1985. Since its creation, there has been many modifications to his initial method, ${ }^{17}$ meaning today there several ways to perform a PDT, as demonstrated in Table 1.

I have decided to write this structured review on the topic of complications associated with both PDT and OST, as I would like to determine whether there is a preferred method or if both carry equal risk. I have collated all of 
the complications encountered during my research and divided them into early, immediate and late as seen below, in Table $2 .{ }^{18}$

\begin{tabular}{|l|l|}
\hline $\begin{array}{l}\text { Year it was } \\
\text { introduced }\end{array}$ & \multicolumn{1}{c|}{ Name/Description of Technique } \\
\hline $\mathbf{1 9 8 5}$ & PDT first introduced by Ciaglia \\
\hline $\mathbf{1 9 9 0}$ & $\begin{array}{l}\text { Griggs } \text { et al developed a technique referred to as the 'guidewire dilator forceps technique'. This } \\
\text { method lost popularity as it had a high incidence of soft tissue damage associated with it. }\end{array}$ \\
\hline $\mathbf{1 9 9 7}$ & $\begin{array}{l}\text { Fantoni described a highly complex alternative method which he termed 'Fantoni Translaryngeal } \\
\text { Tracheostomy'. However due to its complexity, this procedure was advised to only be done by highly } \\
\text { experienced operators. }\end{array}$ \\
\hline $\mathbf{1 9 9 9}$ & $\begin{array}{l}\text { The 'Ciaglia Blue Rhino' technique was introduced by Byhahn in the USA. This method is still widely } \\
\text { used today. }\end{array}$ \\
\hline $\mathbf{2 0 0 2}$ & $\begin{array}{l}\text { Frova is the most recent doctor to introduce a modified method for PDT; he introduced 'PercuTwist', } \\
\text { which is said to be associated with better control for the operator. }\end{array}$ \\
\hline
\end{tabular}

Table 1: This table shows a timeline of the evolution of Ciaglias initial method for performing a percutaneous tracheostomy ${ }^{1}$

\begin{tabular}{|l|l|l|}
\hline Early & Intermediate & Late \\
\hline Bleeding & $\begin{array}{l}\text { Subcutaneous emphysema (associated } \\
\text { with OST) }\end{array}$ & Failure to heal - bleeding \\
\hline Pneumothorax & Excessive purulent exudate at stoma & Blockage - with mucous or fluids \\
\hline $\begin{array}{l}\text { Damage to posterior tracheal } \\
\text { wall }\end{array}$ & Haematoma & Collapsed trachea \\
\hline Oesophageal injury & Dysphagia & Dysphagia \\
\hline $\begin{array}{l}\text { Injury to recurrent laryngeal } \\
\text { nerve }\end{array}$ & Stomal infection & Stricture (narrowed trachea) \\
\hline Infection & Tube/cannula displacement & Development of granulation tissue \\
\hline $\begin{array}{l}\text { Technical failures e.g. false } \\
\text { passage/kinking of guidewire }\end{array}$ & Pneumothorax & Failure to decanulate \\
\hline $\begin{array}{l}\text { Perioperative hypoxia due to } \\
\text { tube obstruction or accidental } \\
\text { decannulation }\end{array}$ & Pneumomediastinum & Tracheoesophageal fistula \\
\hline Fracture of tracheal ring & & Tracheal stenosis \\
\hline Aspiration & Tracheomalacia \\
\hline Air embolus & Pneumonia \\
\hline Loss of airway & Aspiration \\
\hline Hypoxemia/hyercarbia & Tracheoartierial fistula \\
\hline Death & & \\
\hline
\end{tabular}

Table 2: This table summarizes the main complications associated with tracheostomies (both PDT and OST). I have divided them into early (perioperative), intermediate (postoperative) and late depending on when the complication arose 


\section{RESULTS}

Braune and colleagues conducted a retrospective observational study in 2013 in order to determine how safe percutaneous dilatational tracheostomy really is in comparison to open surgical tracheostomy. They studied 118 patients who were all having PDTs performed at the bedside and found that the complication rates were actually very low. From 118 patients, only four patients developed a complication: two suffered with post-procedural major haemorrhage (defined as $>100 \mathrm{ml}$ of blood loss) and two developed a pneumothorax. This finding is a common one amongst the literature, with bleeding being the main complication in many articles. It is made even more difficult with the fact that it is mandatory to supply anticoagulants to surgical patients in order to avoid coagulation however; this of course increases the chances of major haemorrhage. Overall, the complication rate for this trial was $4.2 \%$, with the rate of haemorrhage at $1.7 \%$. They therefore concluded that PDT is a safe procedure to conduct and support its growth in popularity in recent years. ${ }^{19}$

In 2014, the American Journal of Surgery published a report of a review that spanned ten years and looked at trauma patients undergoing tracheostomy. They observed 616 patients, of which 351 underwent PDT and the remaining 265 underwent OST. Again, the aim of their review was to determine if the difference in outcomes of the two tracheostomy methods differed significantly enough to label one as being the 'better option'. After analysis of their results, they found that although the median severity of injuries gained after PDT was slightly higher (26 vs 24 for OST); the overall complication rates were the same for both groups. Despite this, they stated that the mortality rate was higher with open surgical tracheostomy due to the extra stress put on the patient during the transfer to and from theatre. Ultimately, they established that these results meant both methods are equal in risk. ${ }^{20}$

A randomised controlled trial performed in 2014 set out to decide which out of PDT and OST would be the best option for patients admitted to ICU. The trial involved 60 patients, all of whom needed a tracheostomy. Although the trial provided evidence of differences between the two procedures in terms of cost and duration, there were no variances in complication rates between the two. It was concluded that percutaneous dilatational tracheostomy was the method of choice for patients in ICU purely based on the finding that it was a faster procedure to perform, rather than the idea that it had less accompanying complications. ${ }^{15}$

A prospective observational study by Kiran et al. in 2015 compared the short and long-term outcomes of PDT with OST performed at the bedside. Over a three-year period, 90 patients needing a tracheostomy were studied. It is evident from the results table below, that overall there were five complications seen with the OST vs. the seven complications seen with the PDT. This is not a significant difference and so I would agree with their conclusion that there is no statistical dissimilarity between either technique. It is an interesting point that the complications seen were the same for both methods (bleeding and subcutaneous emphysema) which only further supports the inference that there is no real variance in the risks for these procedures. ${ }^{21}$

\begin{tabular}{|l|c|c|c|}
\hline Complications & OST & PDT & Total \\
\hline Bleeding & 5 & - & 5 \\
\hline Emphysema & 2 & - & 2 \\
\hline Paratracheal insertion & - & 1 & 1 \\
\hline Pneumothorax & - & 1 & 1 \\
\hline Tube block & 2 & - & 2 \\
\hline Total complications & 9 & 2 & 11 \\
\hline
\end{tabular}

Table 4: Table showing the complications that occurred in the trial of 32 patients undergoing either open surgical tracheostomy (OST) or percutaneous dilatational tracheostomy (PDT). The numbers in the table represent the quantity of patients that suffered with the complication

\begin{tabular}{|l|c|l|l|l|c|}
\hline \multicolumn{2}{|c|}{ Surgical Tracheostomy } & \multicolumn{2}{c|}{ Percutaneous Tracheostomy } & \multicolumn{2}{c|}{ Both } \\
\hline Complication & Patients (n) & Complication & Patients (n) & Complication & Patients (n) \\
\hline $\begin{array}{l}\text { Minor Bleeding } \\
(<100 \mathrm{ml})\end{array}$ & 2 & Haematoma & 5 & $\begin{array}{l}\text { Formulation of } \\
\text { granulation tissue with } \\
\text { subsequent tracheal } \\
\text { narrowing }\end{array}$ & 13 \\
\hline $\begin{array}{l}\text { Subcutaneous } \\
\text { emphysema }\end{array}$ & 2 & $\begin{array}{l}\text { Subcutaneous } \\
\text { emphysema }\end{array}$ & 2 & $\begin{array}{l}\text { Tracheoesophageal } \\
\text { fistula }\end{array}$ & 1 \\
\hline $\begin{array}{l}\text { Excessive purulent } \\
\text { exudate at stoma }\end{array}$ & 1 & & 7 & & 14 \\
\hline Total & 5 & & & & 1 \\
\hline
\end{tabular}

Table 3: This table shows the results of the study performed by Kiran in $2015 .{ }^{21} \mathrm{I}$ have split the complications up into groups depending on whether they were found with the surgical tracheostomy, the percutaneous tracheostomy or whether they were seen in both 
In a prospective randomised comparative study published in 2005, Kumar et al. stated that PDT is a respectable substitute for OST however; there is no significant evidence to declare that it is a better alternative. They compared the techniques by observing 32 patients undergoing elective tracheostomies: 17 had open surgical tracheostomies and the remaining 15 had percutaneous dilatational tracheostomies. ${ }^{16}$ The results of the study are displayed in the table below (Table 4).

Although all of the inquiries so far have concluded that there is no significant difference in complication rates between PDT and OST, some studies state otherwise. The following cases propose a 'better option' for tracheostomy and argue that percutaneous dilatational tracheostomy is in fact the superior choice.

In 2006, Delaney et al. directed an organized metaanalysis of 1212 cases in 17 clinical trials on this debate. They found PDT to be linked with lower incidences of bleeding complications, wound infection and mortality in comparison to open surgical tracheostomy. ${ }^{22}$

In a 2013 meta-analysis led by Satio et al. it was also claimed that PDT was associated with lower incidences of wound and stoma site infection as well as cosmetic deformities. The analysis looked at 490 percutaneous tracheostomy cases and 484 open surgical tracheostomies. However there wasn't a difference between the two techniques in terms of mortality or bleeding complications. ${ }^{23}$

Despite some articles arguing the idea that PDT is a superior method to OST, I found that the majority literature agrees that both methods are on par when it comes to complication rates.

After evaluating multiple studies, all with similar conclusions, I wanted to determine the current view on this debate and so I reviewed a recent meta-analysis that was performed in 2017 to see what was concluded. The analysis reviewed 109 publications, which included over 25,000 tracheostomies: $67 \%$ of which were percutaneous dilatational tracheostomies. Over the five-year period within which the analysis was completed, 352 deaths were reported, 190 of which were found to be directly related to the tracheostomy. When we standardised these numbers to make it a fair comparison for comparing PDT to OST, the mortality rates for both methods showed no significant difference. It was discovered that the most common complications were haemorrhage, false passage and loss of airway: see Table $5 .^{24}$

\section{DISCUSSION}

In the study by Kumar et al., whose results are presented in Table 4, we can see that the overall incidence of complications was much higher for the open surgical group, with nine complications as opposed to two. ${ }^{16}$ The overall complication rate for the OST patients was $52.9 \%$, which is significantly higher than $13.4 \%$, which is the rate for patients who had a PDT. These results seem reliable and fitting with the current literature. From these outcomes, it could be inferred that percutaneous dilatational tracheostomy is a safer method as it is associated with fewer complications. However, as we know, there are some indications for which PDT would not be suitable e.g. when performing a tracheostomy on a young child, or in an emergency. We could therefore view this as a potential conflict and source of bias, as, if all of the 'high risk' tracheostomies are done using the OST technique, then of course these procedures are going to have an increased chance of incurring complications and so this could prejudice results. It must also be noted that there were more patients undergoing the surgical tracheostomy than the percutaneous tracheostomy; also, the sample size of 32 was very small. These actualities suggest that this study was perhaps unreliable.

As discussed in Table 3, the study released in 2015 by Kiran $^{21}$ showed interesting findings. Although the overall conclusion was that the differences in complication rates were not significant, I think it is important to note that PDT showed more complications than OST. This was the first study I came across in which this was the case and although the difference is not significant, it supports the idea that there really is no clear winner when it comes to picking a 'better' option for this procedure.

A common issue I found when researching the topic was that studies only looked at small numbers of patients. Although I thought the RCT performed by Hasanloei $e t$ al..$^{15}$ was a strong study that provided good evidence, I felt

\begin{tabular}{|l|c|c|c|c|}
\hline Complication & PDT & OST & Method not specified & Total \\
\hline Haemorrhage & 44 & 21 & 0 & 65 \\
\hline Pneumothorax & 15 & 5 & 0 & 20 \\
\hline Injury to posterior tracheal wall and tracheoesophageal fistula & 9 & 3 & 1 & 13 \\
\hline Loss of airway & 33 & 17 & 7 & 57 \\
\hline Bronchospasm & 4 & 0 & 0 & 4 \\
\hline Acute heart failure & 8 & 3 & 3 & 14 \\
\hline Mediastinitis & 7 & 0 & 0 & 7 \\
\hline Total complications & 120 & 49 & 11 & 180 \\
\hline
\end{tabular}

Table 5: The table shows the complications encountered during the tracheostomies including how many patients suffered with each one 
that as the sample size was only 60 this was just not large enough for me to make confident judgements from. A further critique is that the studies often didn't follow up patients after they had left hospital. This was a shame as I feel there is so much more information needed on the long-term complications of tracheostomies.

A common theme highlighted throughout my research was the suggestion to use adjuncts such as a bronchoscopic guidance or real time ultrasound in order to improve the safety and reduce complication rates for both types of tracheostomy. Bronchoscopy allows the operator to visualise and therefore confirm the entry of the needle into the trachea during the procedure, therefore supposedly reducing the risk of injury to the tracheal wall. Similarly, the use of real time ultrasound would provide a visualisation of the neck tissues, allegedly allowing the user to avoid vasculature and reduce risk of haemorrhage. Of course, both of these assistants increase the cost of the procedure and so there is still large debate around whether or not the benefits of using them would be cost effective enough to justify their widespread implantation. ${ }^{25-27}$

Overall, having studied a large array of literature on this topic, I hold the belief that both methods are very similar in terms of their complication rates. I do however appreciate that it is unreliable to judge the methods purely based on their complication rates as there are many other factors that would have to be taken into consideration when choosing a preferred technique. There are of course advantages and disadvantages to both as well as scenarios in which one procedure would outweigh the other as the 'better option'. I have summarised the advantages and disadvantages below (Table 6). The fact that both techniques show similar numbers of disadvantages supports my conclusion that neither technique is superior. ${ }^{828-30}$ Ultimately, irrespective of how many advantages each technique has, the method of choice is completely subjective to the patient and their situation. I would therefore advocate to all health care professionals to make their decision based on the patient rather than letting the generic facts make it for them.

\section{ACKNOWLEDGMENTS}

I would like to say a special thankyou to my convenor, Ms Shadaba Ahmed, for her help, guidance and good advice throughout the production of this review. Not only did she provide excellent supervision and intelligence, but also gave me the opportunity to watch surgeries and attend clinics, both of which were amazing for my own learning and development.

\begin{tabular}{|l|l|l|l|}
\hline \multicolumn{2}{|c|}{ Open Surgical Tracheostomy } & \multicolumn{1}{c|}{ Percutaneous Dilatational Tracheostomy } \\
\hline \multicolumn{1}{|c|}{ Advantages } & \multicolumn{1}{c|}{ Disadvantages } & \multicolumn{1}{c|}{ Advantages } & \multicolumn{1}{c|}{ Disadvantages } \\
\hline $\begin{array}{l}\text { Dissection is done } \\
\text { under direct vision }\end{array}$ & Transport of patient required & $\begin{array}{l}\text { Does not require transport of } \\
\text { patient }\end{array}$ & Requires bronchoscopy \\
\hline $\begin{array}{l}\text { Aberrant vessels can be } \\
\text { avoided. }\end{array}$ & More bleeding & $\begin{array}{l}\text { Less cosmetic deformity (due } \\
\text { to smaller incision) }\end{array}$ & $\begin{array}{l}\text { Risk that the bronchoscope } \\
\text { will cause damage }\end{array}$ \\
\hline $\begin{array}{l}\text { Achieves the best } \\
\text { control of the airway }\end{array}$ & $\begin{array}{l}\text { Increased risk of tracheal } \\
\text { stenosis }\end{array}$ & Less expensive & \\
\hline $\begin{array}{l}\text { Can be done in difficult } \\
\text { situations such as an } \\
\text { emergency, young } \\
\text { children or patients } \\
\text { with difficult anatomy }\end{array}$ & Quicker procedure & \\
\hline & & Better utilisation of resources & \\
\hline & $\begin{array}{l}\text { Less bleeding and infection } \\
\text { (as less trauma to the tissues) }\end{array}$ & \\
\hline & $\begin{array}{l}\text { Can be done by a range of } \\
\text { trained professionals (not just } \\
\text { ENT surgeons) }\end{array}$ & \\
\hline & $\begin{array}{l}\text { Tighter fit of tracheostomy } \\
\text { tube }\end{array}$ & \\
\hline
\end{tabular}

Table 6: A table showing the advantages and disadvantages of both surgical and percutaneous tracheostomy 


\section{REFERENCES}

1. Cabrini L, Monti G, Landoni G, Biondi-Zoccai G, Boroli F, Mamo D, et al. Percutaneous tracheostomy, a systematic review. Acta Anaesthesiologica Scandinavica. 2012;56(3):270-81.

2. Tracheostomy. Nursing Standard. 2014;28(49):19-.

3. Casserly P, Lang E, Fenton JE, Walsh M. Assessment of healthcare professionals' knowledge of managing emergency complications in patients with a tracheostomy. BJA: British Journal of Anaesthesia. 2007;99(3):380-3.

4. Drake R, Vogl AW, Mitchell AWM. Gray's anatomy for students 3rd ed. London: Churchill Livingstone; 2009.

5. Naish J, Court DS. Medical Sciences 2nd ed. Edinburgh: Saunders Elsevier; 2014

6. Mehta C, Mehta Y. Percutaneous tracheostomy. Annals Of Cardiac Anaesthesia. 2017;20(Supplement):S19-S25.

7. Cipriano A, Mao ML, Hon HH, Vazquez D, Stawicki SP, Sharpe RP, et al. An overview of complications associated with open and percutaneous tracheostomy procedures. International Journal of Critical Illness and Injury Science. 2015;5(3):179-88.

8. Johnson-Obaseki S, Veljkovic A, Javidnia H. Complication rates of open surgical versus percutaneous tracheostomy in critically ill patients. Laryngoscope. 2016:2459-67.

9. Hodgson RE, Pillay TK. Awake percutaneous tracheostomy as an alternative to open emergency tracheostomy in a threatened airway. Southern African Journal of Anaesthesia and Analgesia. 2017;23(5):123-8.

10. Domènech I, Cruz Toro $\mathrm{P}$, Tornero J, Giordano A, Callejo À. Analysis of predisposing factors for complications of percutaneous tracheostomy. Ear, Nose \& Throat Journal. 2015;94(8):312-8.

11. Raimondi N, Vial MR, Calleja J, Quintero A, Cortés A, Celis E, et al. Evidence-based guidelines for the use of tracheostomy in critically ill patients. Journal of Critical Care. 2016 38:304-18.

12. Durbin CG. Techniques for performing tracheostomy. Respiratory Care. 2005;50(4):488.

13. Groves DS, Durbin CG, Jr. Tracheostomy in the critically ill: indications, timing and techniques. Current Opinion in Critical Care. 2007;13(1):90-7.

14. Fradis M, Malatskey S, Dor I, Krimerman S, Joachims HZ, Ridder GJ, et al. Early complications of tracheostomy performed in the operating room. The Journal Of Otolaryngology. 2003;32(1):55-7.

15. Hasanloei M, Mahoori A, Bazzazi A, Golzari S, Karami T. Percutaneous dilatational tracheostomy and surgically created tracheostomy in ICU patients. Journal of Cardiovascular and Thoracic Research. 2014;6(1):43-6.

16. Kumar AR, Mohanty S, Senthil K, Gopinath M. Comparative study of percutaneous dilatational tracheostomy and conventional tracheostomy in the intensive care unit. Indian Journal of Otolaryngology and Head and Neck Surgery: Official Publication of The Association of Otolaryngologists of India. 2005;57(3):202-6.
17. Cools-Lartigue J, Aboalsaud A, Gill H, Ferri L. Evolution of percutaneous dilatational tracheostomy-a review of current techniques and their pitfalls. World Journal Of Surgery. 2013;37(7):1633-46.

18. Jarosz K, Kubisa B, Andrzejewska A, Mrówczynska K, Hamerlak Z, Bartkowska-Sniatkowska A, et al. Adverse outcomes after percutaneous dilatational tracheostomy versus surgical tracheostomy in intensive care patients: case series and literature review. Therapeutics \& Clinical Risk Management. 2017;13:975-81.

19. Braune S, Kienast S, Hadem J, Wiesner O, Wichmann D, Nierhaus A, etal. Safety of percutaneous dilatational tracheostomy in patients on extracorporeal lung support. Intensive Care Medicine. 2013;39(10):17929.

20. Kettunen WW, Helmer SD, Haan JM. Incidence of overall complications and symptomatic tracheal stenosis is equivalent following open and percutaneous tracheostomy in the trauma patient. The American Journal of Surgery. 2014;208(5):770-4.

21. Kiran S, Eapen S, Chopra V. A comparative study of complications and long term outcomes of surgical tracheostomy and two techniques of percutaneous tracheostomy. Indian Journal of Critical Care Medicine. 2015;19(2):82-6.

22. Delaney A, Bagshaw SM, Nalos M. Percutaneous dilatational tracheostomy versus surgical tracheostomy in critically ill patients: a systematic review and meta-analysis. Crit Care. 2006;10(2):R55.

23. Saito K, Morisaki H. Percutaneous dilatational tracheostomy: collaborative team approach for safe airway management. Journal of Anesthesia. 2013;27(1):161-5

24. Klemm E, Nowak AK. Tracheotomy-related deaths. Deutsches Arzteblatt International. 2017;114(16):273-9.

25. Gadkaree SK, Schwartz D, Gerold K, Kim Y. Use of bronchoscopy in percutaneous dilationalt. JAMA Otolaryngology-- Head \& Neck Surgery. 2016;142(2):143-9.

26. Rajajee V, Williamson CA, West BT. Impact of real-time ultrasound guidance on complications of percutaneous dilatational tracheostomy: a propensity score analysis. Critical Care. 2015;19(1):198.

27. Oberwalder M, Weis H, Nehoda H, Kafka-Ritsch R, Bonatti H, Prommegger R, et al. Videobronchoscopic guidance makes percutaneous dilational tracheostomy safer. Surgical Endoscopy. 2004;18(5):839-42.

28. Yaghoobi S, Kayalha H, Ghafouri R, Yazdi Z, Khezri $\mathrm{MB}$. Comparison of complications in percutaneous dilatational tracheostomy versus surgical tracheostomy. Global Journal of Health Science. 2014;6(4):221-5.

29. Putensen C, Theuerkauf N, Guenther U, Vargas M, Pelosi P. Percutaneous and surgical tracheostomy in critically ill adult patients: a meta-analysis. Critical Care. 2014;18(6):544.

30. Gilbey P. Fatal complications of percutaneous dilatational tracheostomy. American Journal of Otolaryngology. 2012;33(6):770-3.

Correspondence to: shadaba.ahmed@mbht.nhs.uk 